\title{
Stabilization of Expansive Soil Using Wheat Husk Ash and Granulated Blast Furnace Slag
}

\author{
Khaja moniuddin ${ }^{1 *}$ and Chethan $\mathrm{K}^{2}$ \\ ${ }^{1}$ Assistant Professor, Department of Civil Engineering, India \\ ${ }^{2}$ Assistant Professor, Department of Civil Engineering, India
}

Received: 制 January 25, 2018; Published: 漹 February 06, 2018

*Corresponding author: Khaja Moniuddin, Assistant Professor, Department of Civil Engineering, BKIT, Bhalki, Karnataka, India

\begin{abstract}
The Expansive soil swells when it comes in contact with water and shrinks on drying. These soils are characterized by inherent swelling and shrinkage characteristics due to presence of Montmorillonite clay mineral, which exhibits volume change behavior under changes of moisture content. Granulated blast furnace slag(GBS) is the waste material which is generated from the steel plant after with the increase in waste disposal problems and their solutions has increased to a where the waste disposal by several methods has become a technology of its own. To minimize the impact of wastes on the environment, final disposal which offers environmentally sustainable methodology for disposing wastes on land is inevitable, after thorough analysis of behavior of soils. Hence, an attempt has been made in the investigation to overcome the disposal problems of GBS that are mixed with wheat husk ash to achieve the desired requirements. In the same way the Expansive soils are treated with different percentage of GBS and wheat husk ash to improve the engineering properties of soil.
\end{abstract}

\section{Introduction}

Expansive soils, well-known as Black Cotton Soils in India, occupy about one-fifth of land area of the country. Black Cotton Soils are residual deposits formed from basalt or trap rocks. Expansive soil contain significant amount of montmorillonite material. These soils are very hard in dry state but lose their load carrying capacity when once they are comes in contact with water. They have high shrinkage and swelling characteristics. In general, these expansive soils are very much keen to changes in environment. The environment includes the stress system, the chemistry of pore water in the system, the seasonal variations in ground water table with consequent changes in natural moisture content and temperature variations. These swelling and shrinkage properties have made the soil unsuitable for civil engineering purposes either as foundation or embankment material.

The compaction is a mechanical process in which the densification is achieved through the expulsion of air voids at almost constant water content of the soil mass. However, densification through consolidation is primarily attributed to the gradual expulsion of pore water from the voids of the soil mass undergoing consolidation and to the increase in the effective stress on the soil mass. Stabilizing agents such as fly ash, quarry dust and rice husk ash are used for the stabilization of expansive soils. In the same way GBS is one of the materials used as stabilizing agent [1-5].

Soil properties that influence shrink-swell potential: The influence of shrink-swell potential depends on the following factors:

a. Clay Mineralogy: Clay minerals which cause soil volume changes are montmorillonite, vermiculites and some mixed layer minerals. Illites and kaolinites are infrequently expansive, but can cause volume changes when particle sizes are extremely fine.

b. Dry Density: Higher densities indicate closer particle spacing, which may greater repulsive forces between particles and larger swelling potential.

c. Plasticity: In general, soils that exhibit plastic behavior wide ranges of moisture content and that have high liquid limits have greater potential for swelling and shrinking. Plasticity is an indicator of swell potential. 
Soil water chemistry: swelling is depressed by increased cat ion concentration and increased cat ion valence.

Ground water: Shallow water tables provide a source of moisture and fluctuating water tables contribute to moisture.

Permeability: Soils with higher permeability, particularly due to fissures and cracks in the field soil mass, allow faster migration of water and promote faster rates of swell.

Temperature: increasing temperatures cause moisture to diffuse to cooler areas beneath pavements and buildings.

\section{Laboratory tests used for identification of expansive soils}

In Engineering practice, the common identification schemes are based on standard classification results, such as grain size analysis and Atterberg's limits. However, other tests such as microscopic examination, X-Ray diffraction and differential thermal analysis for identifying the type and amount of minerals used in identifying potentially swelling soils (Table 1.1).

Table 1.1: Laboratory tests used in identification of Expansive soils.

\begin{tabular}{|c|c|c|c|}
\hline Test & Reference & Properties Investigated & Parameters Determined \\
\hline Liquid Limit & ASTM D-4308 & Upper limit water content of plasticity & PI=LL - PL $=$ Plasticity Index \\
\hline Plastic Limit & ASTM D-4318 & Lower limit water content of plasticity & LI $=((\mathrm{w}-\mathrm{LL})) /((\mathrm{LL}-\mathrm{PL}))$ \\
\hline Shrinkage Limit & ASTM D-427 & Lower limit water content of soil shrinkage & R= Shrinkage ratio \\
\hline Clay Content & ASTM D-422 & Distribution of fine grained particle sizes & Percent finer than $2 \mu \mathrm{m}$ \\
\hline Free Swell Test & Holtz and Gibbs & $\begin{array}{c}\text { Swell upon wetting of unconsolidated unconfined sample of } \\
\text { air dried soil }\end{array}$ & FS $=(($ Vwet-Vdry $)) /$ Vdry $\times 100 \%$ \\
\hline
\end{tabular}

\section{Physical properties of expansive soils}

The typical characteristics of Expansive soil are shown in Table 1.2

Table 1.2: Physical properties of expansive soils (Anand, KS 1989).

\begin{tabular}{|c|c|}
\hline Density & $\mathbf{1 . 3}$ to $\mathbf{1 . 7 5 g m / c c}$ \\
\hline Natural water content & $20 \%$ to $40 \%$ \\
\hline pH value & 8.5 (Alkaline) \\
\hline Activity & 0.8 to 1.50 \\
\hline Atterberg limits & Liquid limit $50 \%$ to $120 \%$ \\
\hline Plastic limit 20\% to $60 \%$ & \\
\hline Plasticity index $30 \%$ to $60 \%$ & \\
\hline Shrinkage limit $9 \%$ to $18 \%$ & \\
\hline Unified Soil Classification & CH to MH \\
\hline Specific gravity & 2.60 to 2.75 \\
\hline Proctor density (vd) & 1.35 to $1.60 \mathrm{gm} / \mathrm{cc}$ \\
\hline Optimum moisture content & $20 \%$ to $35 \%$ \\
\hline Free swell & $40 \%$ to $180 \%$ \\
\hline Shrinkage Index & 40 to 100 \\
\hline
\end{tabular}

\section{Methods of stabilization}

The stabilization techniques may be grouped under the following two major heads

\section{A. Stabilization without additives \\ B. Stabilization with additives}

Stabilization without additive may be mechanical rearrangement of particles through compaction or addition or removal of soil particles [6,7]. Some of the stabilization process can be studied as follows:

\section{Chemical stabilization}

Besides the use of lime, other chemicals both organic and inorganic can be used to stabilize the expansive soils. But the cost of cement stabilization is considerably more than that of lime stabilization. GBS is added to the soil-lime mixture to increase pozzolanic reaction. Chemical like potassium, deactivation of sulphates with calcium chloride, water proofing with silicones or asphalts, cementation with silicates, carbonates all proved in reduction of plasticity index.

\section{Wheat husk ash}

India wheat husk ash for stabilization appears to be successful solution, wheat husk ash is readily available. Primarily being siliceous material act as pozzolona. Hence in this investigation the compressibility behaviour of black cotton soil treated with GBS and wheat husk ash has been studied. Wheat husk ash is obtained by burning locally available wheat husk in an open kiln for about twenty four hours. After complete burning, the burnt material was sieved through I.S.425 micron sieve and minus 425 -fraction was taken for the study.

\section{Materials used}

For the present study, Expansive soil, GBS and wheat husk ash have been used. Their physical properties have been determined.

\section{Expansive soil}

In India, $20 \%$ of surface deposits are covered with expansive soils. The Expansive soil swells when it comes in contact with water and shrinks on drying. These soils are characterized by inherent swelling and shrinkage characteristics due to presence of Montmorillonite clay mineral, which exhibits volume change behaviour under changes of moisture content. Due to characterized swelling and shrinkage behaviour of expansive soils leads to the 
severe damages to the Civil Engineering structures such as cracking in buildings or total distractions of the structure, foundations and pavements. For the present investigation the Expansive soil was obtained from Rudnoor village, Bhalki taluka, Bidar district, Karnataka state, India. It is collected from an open excavation at a depth of $0.5 \mathrm{~m}$ below the natural ground surface. The soil was air dried and pulverized. This pulverized soil passed through 425 micron IS sieve has been used for this investigation.

\section{Granulated blast furnace slag}

Granulated blast furnace slag (GBS) was obtained from Kirloskar steel plant district Koppal, Karnataka, India. GBS is the waste material which is generated from the steel plant after with the increase in waste disposal problems and their solutions has increased to a where the waste disposal by several methods has become a technology of its own. To minimize the impact of wastes on the environment, final disposal which offers environmentally sustainable methodology for disposing wastes on land is inevitable, after thorough analysis of behaviour of soils [8-9].

\section{Wheat husk ash}

Wheat husk ash is obtained from Byalahalli village, Bhalki taluka, Bidar district in Karnataka state in India by burning locally available wheat husk in an open kiln for about twenty four hours. After complete burning, the burnt material was sieved through I.S.425 micron sieve and minus 425 -fraction was taken for the study.

\section{Results and Discussion}

The liquid limit, plastic limit, shrinkage limit and compaction tests were conducted based on the experimental programme. The effect of additives on index and compaction properties of expansive soil treated with various percentages of GBS and WHA have been studied. The results and discussions are presented in the following section (Table 1.3).

Table 1.3: Physical properties of Expansive soil.

\begin{tabular}{|c|c|}
\hline Properties & Expansive soil \\
\hline Colour & Black \\
\hline Specific Gravity & 2.65 \\
\hline Grain Size Distribution & Well graded \\
\hline Atterberg's Limit & 65.5 \\
Liquid Limit (\%) & 33.2 \\
Plastic Limit (\%) & 32.3 \\
Plasticity Index (\%) & 10.45 \\
\hline Shrinkage Limit (\%) & $\mathrm{CH}$ \\
\hline Unified Classification & 14.92 \\
\hline Compaction Characteristics & 22 \\
\hline Maximum Dry Density (kN/m $\left.{ }^{3}\right)$ & 219.18 \\
\hline Optimum Moisture Content $(\%)$ & \\
\hline Unconfined Compressive Strength $\left(\mathrm{kN} / \mathrm{m}^{2}\right)$ & \\
\hline
\end{tabular}

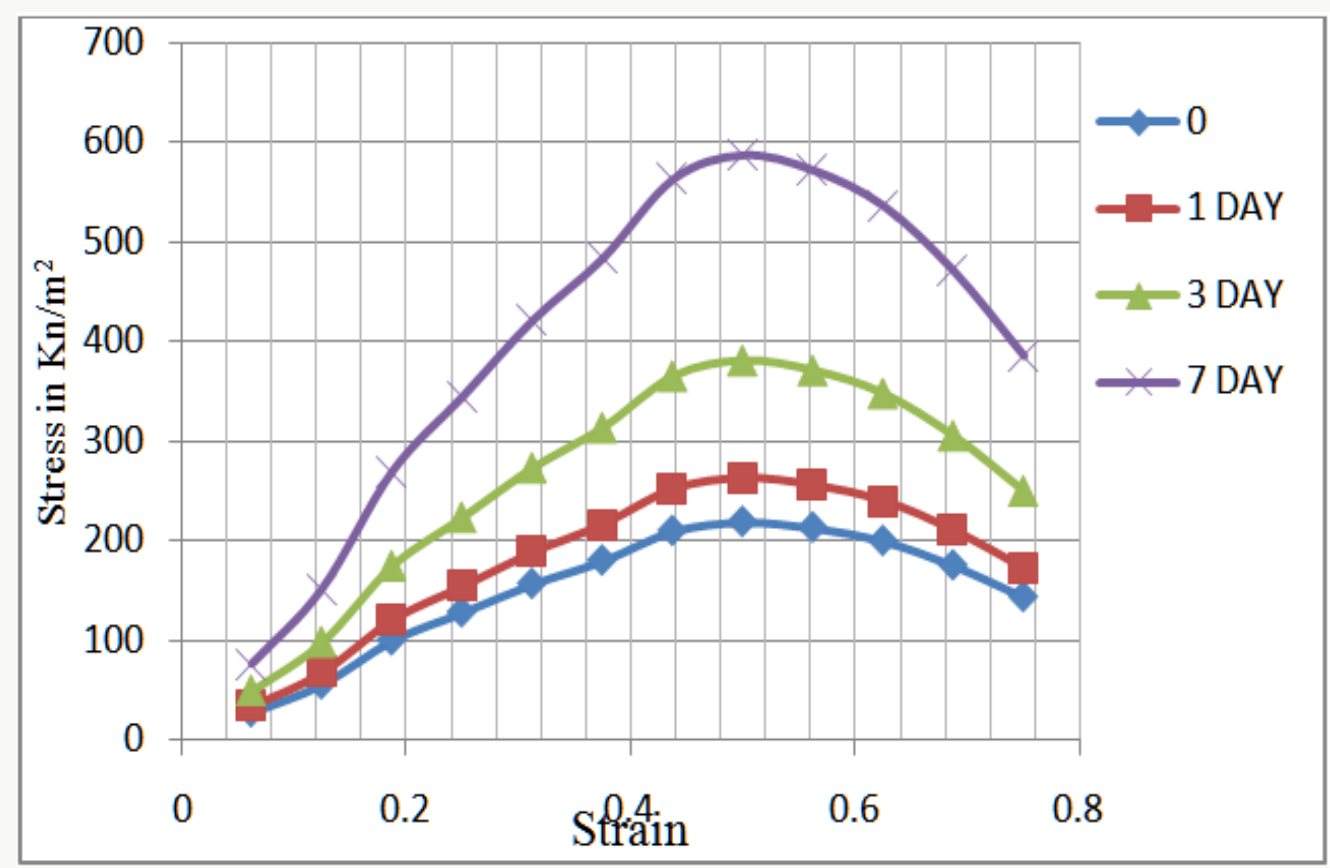

Figure 1: UCS for 3\% of Wheat Husk Ash for different days.

From above figure 1 it shows the stress against strain for 3\% WHA stabilizer. For different days, as strain increases stress also increases up to a limit, afterwards it decreases. This is more effective for 7 day.
From the above figure 2 it shows the stress against strain for $6 \%$ WHA stabilizer. For different days, as strain increases stress also increases up to a limit, afterwards it decreases. This is more effective for 7 day. 


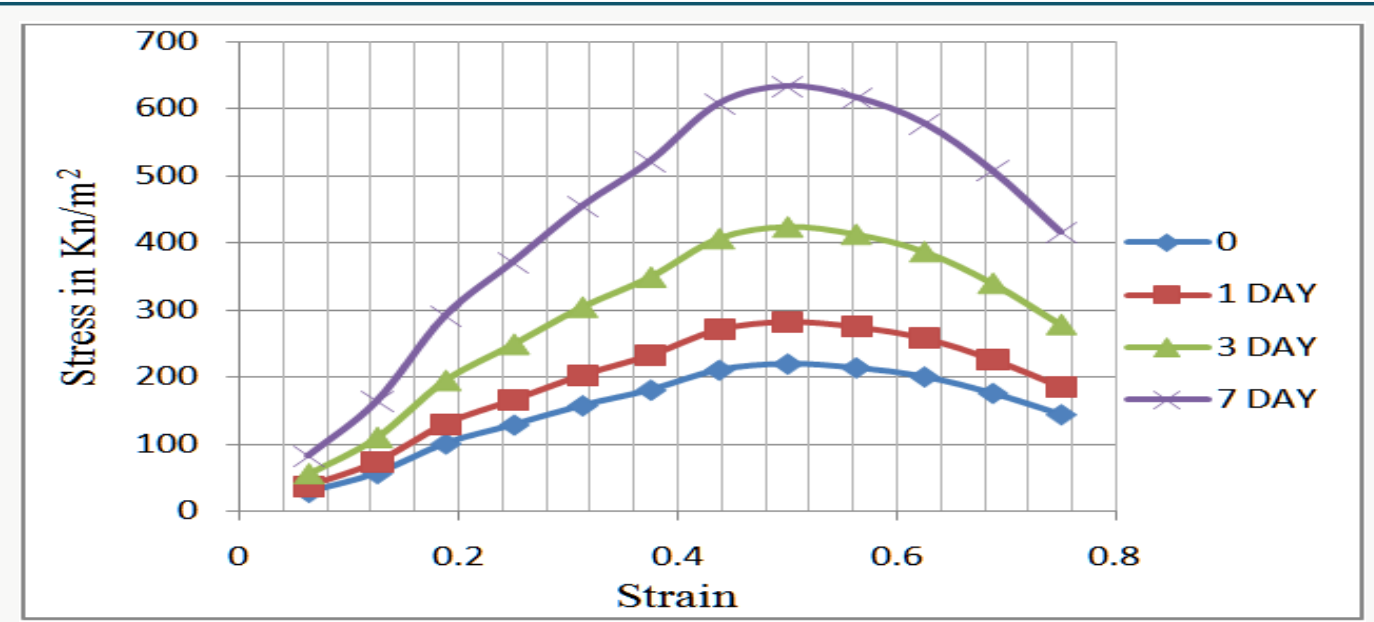

Figure 2: UCS for 6\% of Wheat Husk Ash for different days.

From above figure 3 it shows the stress against strain for 9\% WHA stabilizer. For different days, as strain increases stress

also increases up to a limit, afterwards it decreases. This is more effective for 7 day.

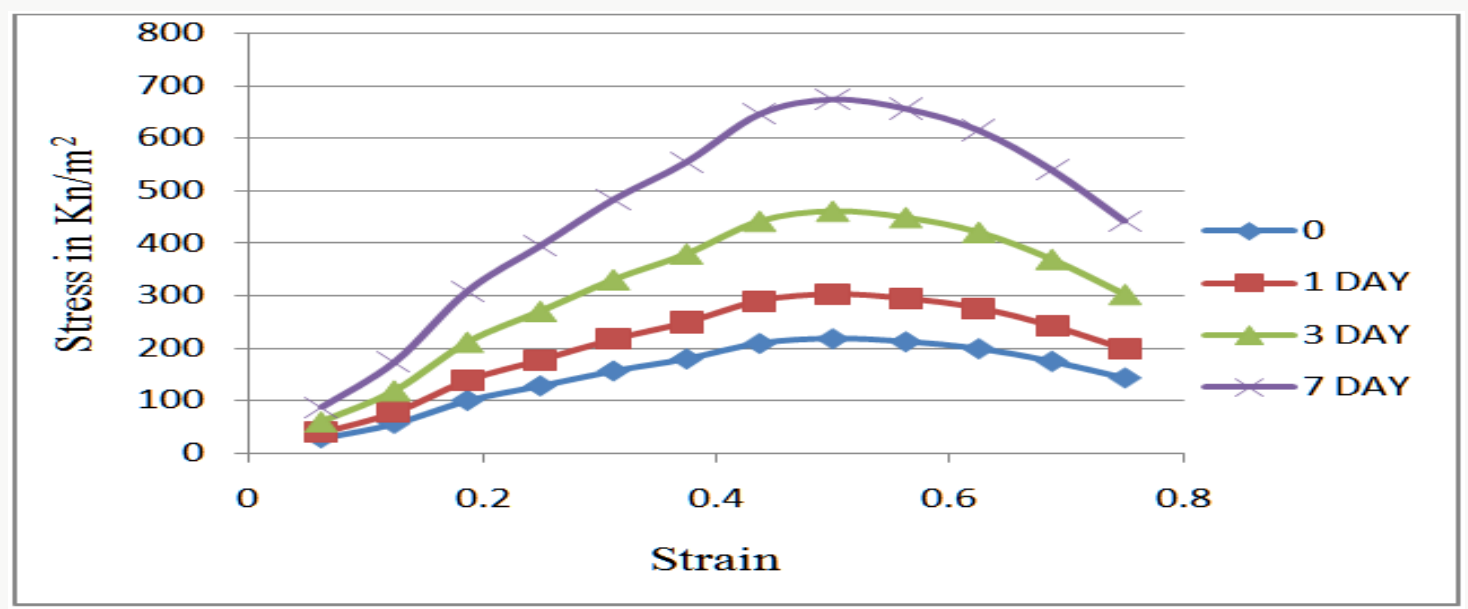

Figure 3: UCS for $9 \%$ of Wheat Husk Ash for different days.

From above figure 4, the stress against strain for 12\% WHA up to a limit, afterwards it decreases. This is more effective for 7 stabilize. For different days, as strain increases stress also increases day.

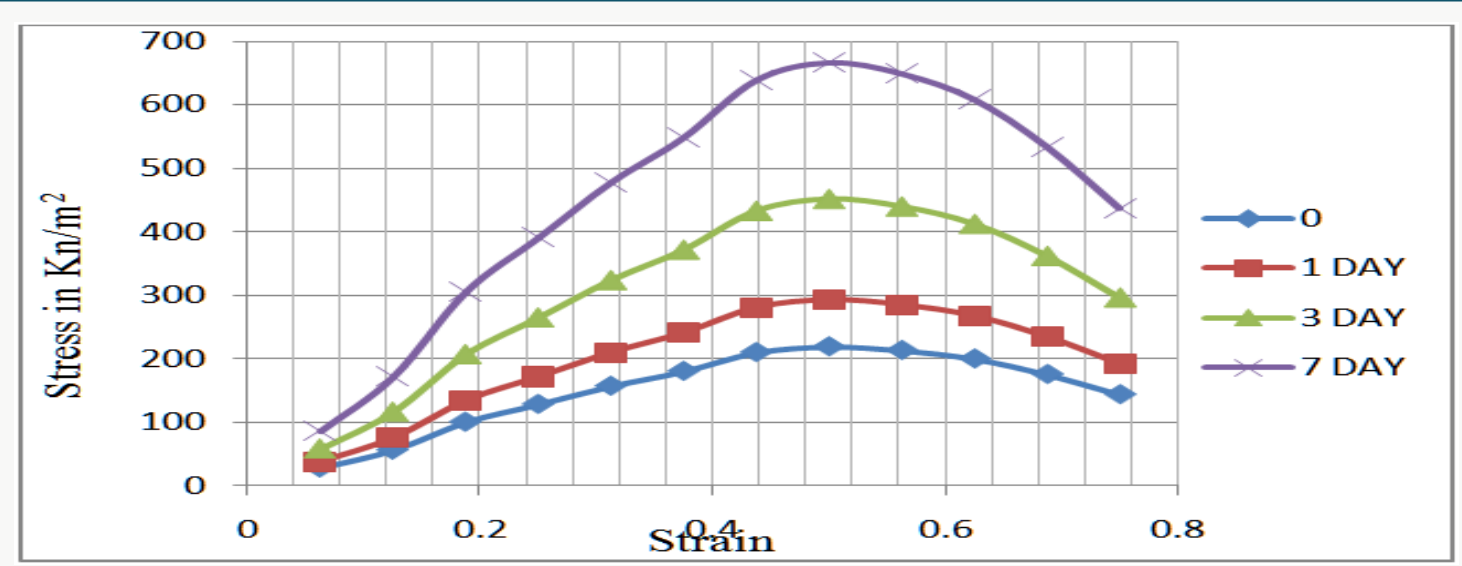

Figure 4: UCS for $12 \%$ of Wheat Husk Ash for different days.

From the Figure 5, the stress against strain for different of \% WHA stabilizer. For 1 day, as strain increases stress also increases

up to a limit, afterwards it decreases. This is more effective for $9 \%$ WHA stabilizer. 


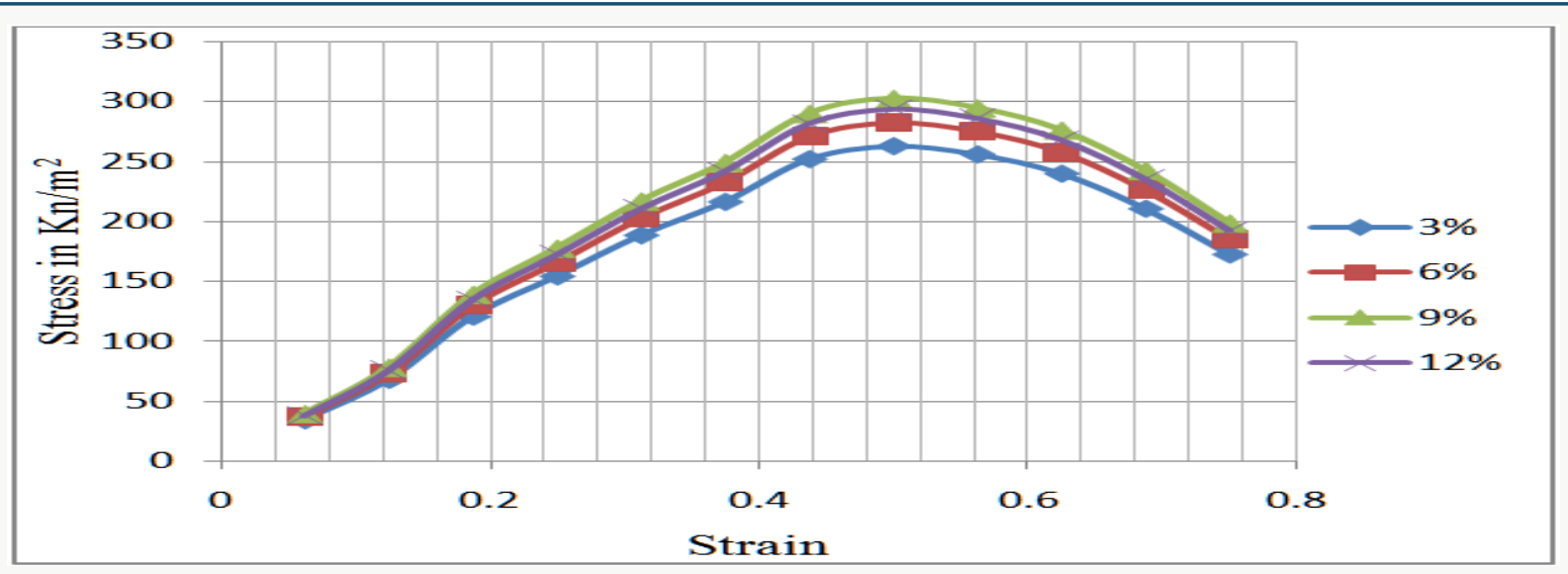

Figure 5: UCS for 1 day for different \% of Wheat Husk Ash.

From the Figure 6 the stress against strain for different of $\%$ WHA stabilizer. For 3 day, as strain increases stress also increases

up to a limit, afterwards it decreases. This is more effective for $9 \%$ WHA stabilizer .

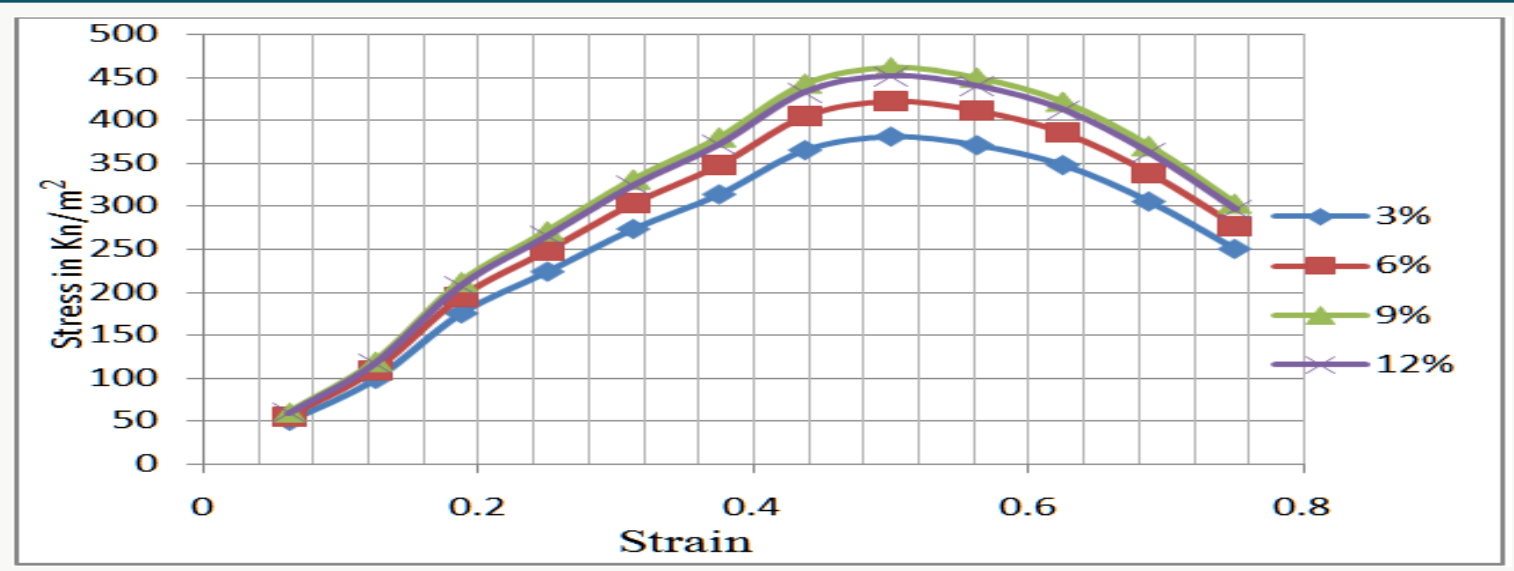

Figure 6: UCS for 3 day for different \% of Wheat Husk Ash.

From the above figure 7, the stress against strain for different of $\%$ WHA stabilizer. For 7 day, as strain increases stress also increases

up to a limit, afterwards it decreases. This is more effective for $9 \%$ WHA stabilizer.

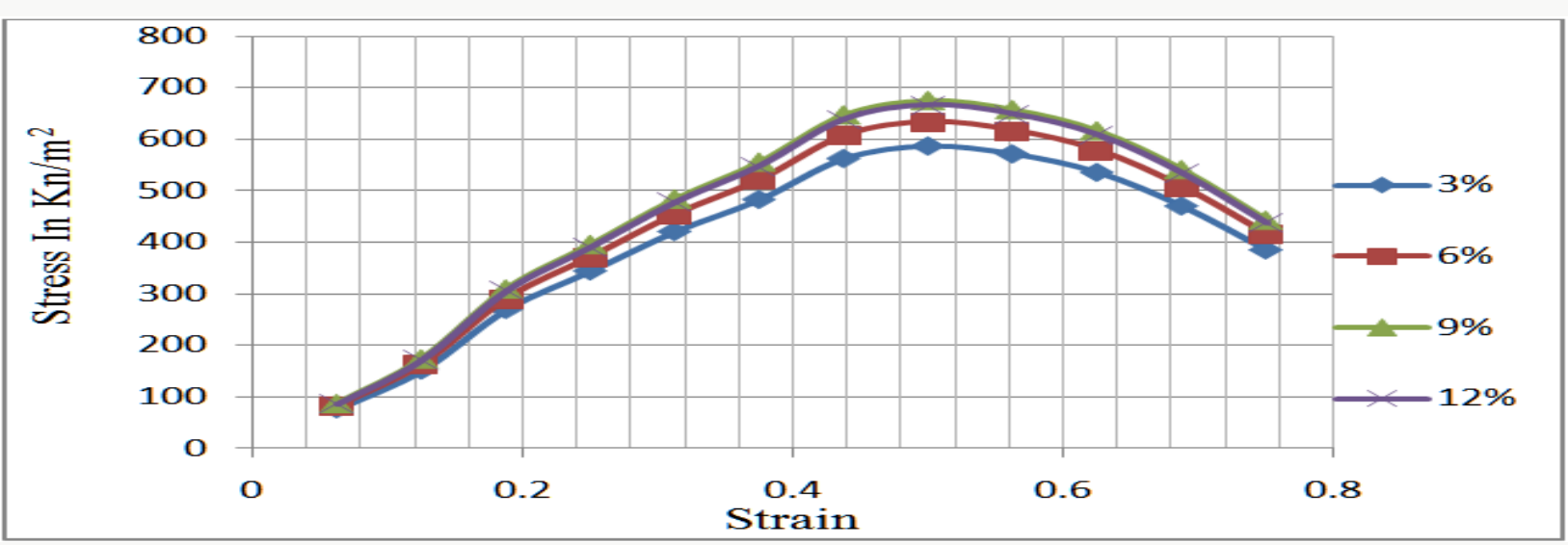

Figure 7: UCS for 7 day for different \% of Wheat Husk Ash.

Figure 8 shows the stress against strain for different days. For optimum (9\%) of WHA, as strain increases stress also increases up to a limit, afterwards it decreases. This is more effective for 7 days.
Figure 9 shows the stress against different days for varying \% WHA. For varying \% of WHA, as number of days increases stress also increases. This is more effective for 7 days [10-12]. 


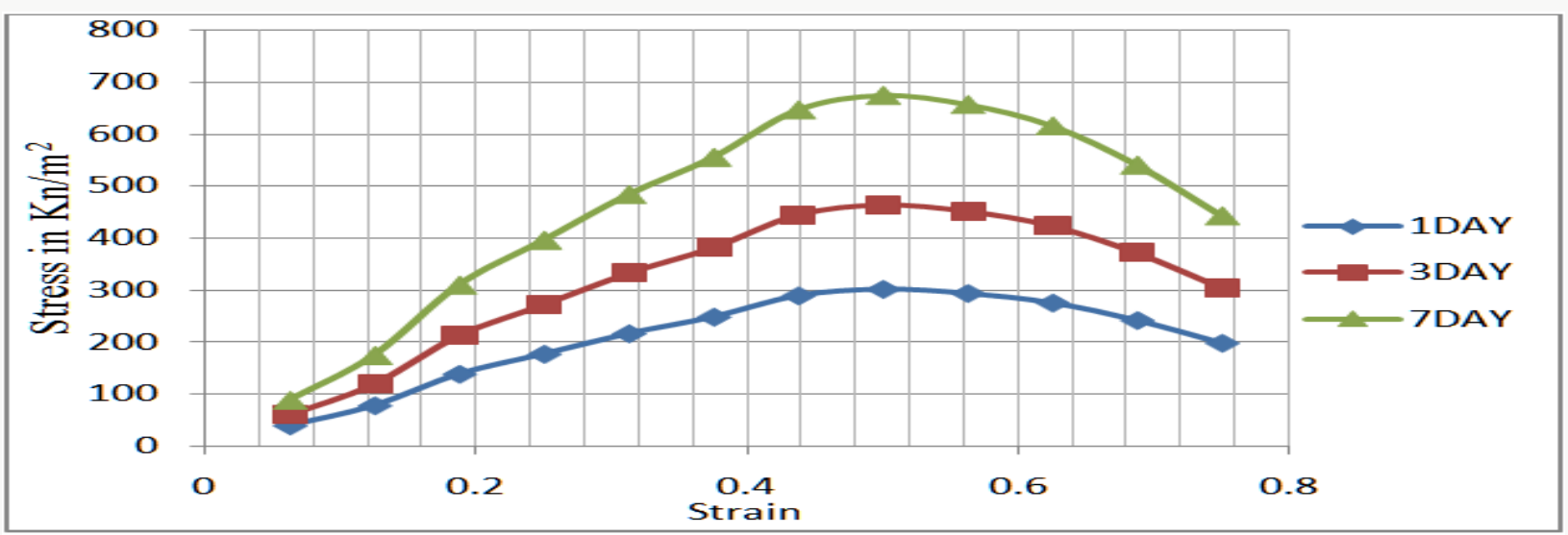

Figure 8: UCS for Wheat Husk Ash at 9\% for different days.

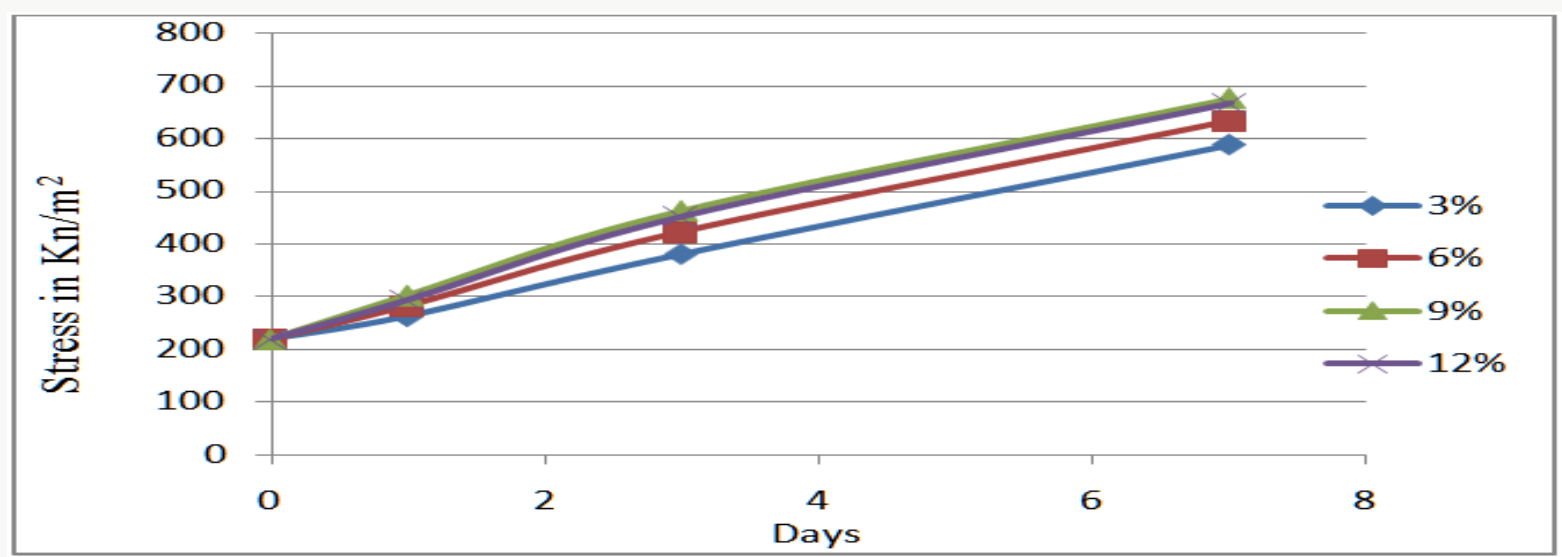

Figure 9: UCS for varying \% of Wheat Husk Ash.

\section{Conclusion}

i) The stress against strain for 3\% WHA stabilizer. For different days, as strain increases stress also increases up to a limit, afterwards it decreases. This is more effective for 7 day.

ii) The stress against strain for 6\% WHA stabilizer. For different days, as strain increases stress also increases up to a limit, afterwards it decreases. This is more effective for 7 day.

iii) The stress against strain for 9\% WHA stabilizer. For different days, as strain increases stress also increases up to a limit, afterwards it decreases. This is more effective for 7 day.

iv) The stress against strain for $12 \%$ WHA stabilizer. For different days, as strain increases stress also increases up to a limit, afterwards it decreases. This is more effective for 7 day.

v) The stress against strain for different of \% WHA stabilizer. For 1 day, as strain increases stress also increases up to a limit, afterwards it decreases. This is more effective for $9 \%$ WHA stabilizer.

vi) The stress against strain for different of \% WHA stabilizer. For 3 day, as strain increases stress also increases up to a limit, afterwards it decreases. This is more effective for 9\% WHA stabilizer.

vii) The stress against strain for different of \% WHA stabilizer. For 7 day, as strain increases stress also increases up to a limit, afterwards it decreases. This is more effective for 9\% WHA stabilizer.

viii) The stress against strain for different days. For optimum (9\%) of WHA, as strain increases stress also increases up to a limit, afterwards it decreases. This is more effective for 7 days.

ix) The stress against different days for varying \% WHA. For varying $\%$ of WHA, as number of day's increases stress also increases. This is more effective for 7 days.

$\mathrm{x}$ ) The stress against strain for different of \% GBS stabilizer. For 1 day, as strain increases stress also increases up to a limit, afterwards it decreases. This is more effective for 9\% GBS stabilizer

xi) The stress against strain for different of \% GBS stabilizer. For 3 day, as strain increases stress also increases up to a limit, afterwards it decreases. This is more effective for 9\% GBS stabilizer. 
xii) The stress against strain for different of \% GBS stabilizer. For 7 day, as strain increases stress also increases up to a limit, afterwards it decreases. This is more effective for 9\% GBS stabilizer.

By adding optimum 9\% WHA and 9\% GBS the water content decreases and dry density increases more effectively.

\section{References}

1. Ali (2004) Carried out an investigation to study the influence of RHA and lime on Atterberg limits, strength.

2. Arpita V Patel (2011) Studied the interaction behavior of typical CH type Expansive soil and castor oil as contaminant.

3. Celik, Nalbantoglu (2013) Had studied the effects of ground granulated blast furnace slag on IP, linear shrinkage (LS), and SP of lime stabilized sulphate-bearing expansive soil.

4. Muntohar (2002) Carried out a series of laboratory experiments individually and in combination of RHA and lime in stabilizing expansive soils in Indonesia.
5. Osinubi (2012) Effect of compaction delay on strength characteristics of black cotton soil stabilized with blast furnace slag and cement.

6. Ramaiah (1972) Behavior of Black cotton soil admixed with lime and rice-husk ash invarious proportions.

7. Rajan (1982) in Karnataka engineering research station, Krishnarajasagara. It was felt that rice-husk ash behaves as pozzolanic material in the presence of lime.

8. Sivanna (1977) Investigated consolidation characteristics of block cotton soil admixed with lime and rice-husk ash.

9. Sharma, Sivapullaiah (2012) Effects of ground granulated blast furnace slag on UCS of expansive soil 2720.

10. Sivapullaiah PV, Sridharan A (1986) Liquid limit of soil mixtures, ASTM, Geotechnical Testing Journal 8: 11-116.

11. Terzaghi K (1943) Theoretical Soil Mechanics, John Wiley and Sons, New York, USA.

12. Wild (2011) Use of GGBS to highway and other foundation layers by determining the beneficial effect.

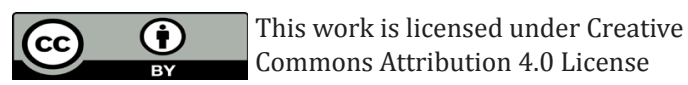

To Submit Your Article Click Here: Submit Article

DOI: 10.32474 /TCEIA.2018.01.000108

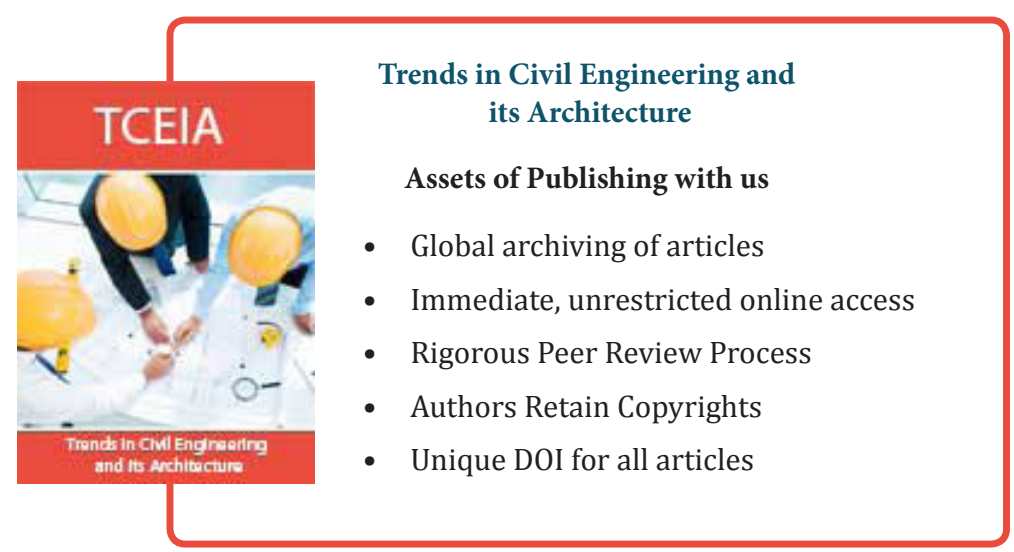

